\title{
The impact of 2009 typhoon Ketsana on nutritional status of children below five years in Southern Laos
}

\author{
Joweria Nambooze, Miho FUJIMURA and Tsukasa INAOKA
}

This study assessed the nutritional status of children below 5 years pre-post typhoon Ketsana in the Oy ethnic group of Southern Laos.

A prospective cross-sectional survey using a pre-post design was used. Structured questionnaires were used to obtain information on household food consumption and anthropometric measurements were carried out.

There was $30 \%$ loss of domestic animals and $50 \%$ reduction in the average rice production with $20 \%$ of the households harvesting no rice at all. This affected the already strained food security situation. No significant difference was however seen between food consumption frequency pre-post typhoon Ketsana. Among the 18 subjects compared, prevalence of stunting and underweight was high (66.7\% and $55.6 \%$ pre typhoon and $61.1 \%$ and $55.6 \%$ post typhoon respectively) and a McNemar test showed that the prevalence of wasting significantly decreased post typhoon Ketsana $(p<0.01)$ whereas the prevalence of stunting and underweight didn't significantly change pre-post typhoon Ketsana $(\mathrm{p}>0.05)$.

The nutritional status of the children was stable post the typhoon Ketsana. This could be attributed to the numerous coping strategies applied in order to have enough food to eat and the fact that the effect of the typhoon could not be seen within such a short period of time.

Key words : nutritional status, food security, typhoon Ketsana, Southern Laos, children below 5 years

\section{Introduction}

Childhood undernutrition remains highly prevalent in developing countries with 178 million children less than 5 years of age estimated to be stunted, 112 million estimated to be underweight and 55 million estimated to be wasted in 2005 (Black et. al., 2008). It is also estimated that more than half of the children who die before the age of five are mildly or moderately malnourished (Pelletier et. al, 1993). The nutritional status of a population depends on the availability of food, its consumption, and its biological utilization.
A natural disaster may affect the nutritional status of a population by affecting one or more components of the food chain depending on the type, duration, and extent of the disaster, as well as the food and nutritional conditions existing in the area before the catastrophe (PAHO, 2000). According to Strauss and Thomas (1998), there is a large body of literature on the determinants of child health but very few studies actually specifically look at the impact of shocks on child growth. Hoddinot and Kinsey (2001) show evidence that temporary shocks can have lasting effects. They show the impact of drought on height growth

The United Graduate School of Agricultural Sciences, Kagoshima University 
among children in Zimbabwe. Their findings show that children aged 12-24 months during the drought lose up to $2 \mathrm{~cm}$ of growth in the short term and this difference is still evident at least 4 years following the end of the drought. Foster (1995) and Deolalikar (2005) also assess the impact of external shocks on children's weight in Bangladesh. A significant impact is mostly seen among poor children.

Laos has one of the worst malnutrition rates in the world. According to the 2008 figures of the Ministry of Health (2009), 40.4\% of the children in Laos are stunted, $37.1 \%$ are underweight and $6.5 \%$ are wasted. The status of children under the age of 5 in rural areas in particular is alarming. The WFP Comprehensive Food Security and Vulnerability Analysis report (CFSVA) (2007) indicates that $31 \%$ of them are underweight and $8 \%$ are wasted. According to Pernille (2006), the causes of malnutrition in Laos are multidimensional and some surveys indicate that it is not the lack of food but the wrong combination which is the main cause of malnutrition and poor childhood development. Other studies show that malnutrition is as a result of extreme and chronic poverty but none of these studies stresses the impact of food insecurity on malnutrition. According to the UN System High level task force report (United Nations, 2009), food insecurity is prevalent in many areas of Laos with $50 \%$ of rural households at risk of becoming food insecure in case of loss of access to natural resources, floods and droughts. The main causes of food insecurity in Laos include natural disasters, unexploded ordinance and poverty. According to Akoto et. al (2010), household food insecurity can negatively affect food consumption, including reduced dietary variety, nutrient intake and nutritional status of household members. Very few studies have been done on the association between natural disasters and food security as well as nutritional status of children below 5 years in the Laos.

The 2006 Ministry of Health of the Goverment of the Lao PDR MICS (Multiple Indicator Cluster Survey) and 2007 WFP CFSVA surveys report that the southern provinces of Laos have the highest rate of under-five malnutrition and the lowest rate of exclusive breastfeeding practice with $46 \%$ stunting and $17 \%$ initiation of breastfeeding within one hour compared with $40 \%$ and $30 \%$ at the national level.

In September 2009, Southern Laos was hit by typhoon Ketsana which caused widespread destruction of paddy fields, granaries and domestic animals. This was the first high-magnitude flood in the southern provinces since 1968 and very few mitigation measures were in place. Typhoon Ketsana struck during the lean season in food insecure provinces of the country with high rates of stunting, at a time when household food stocks were at their lowest levels as farmers prepared for the upcoming harvest. This exacerbated an already delicate food security situation. The current study sets out to assess the household food security situation and nutritional status of children below 5 years pre-post the typhoon Ketsana and also compare pre-post nutritional status and food consumption frequencies of some of the subjects to find out whether there were any changes as a result of the typhoon.

\section{Methods}

\section{Subjects and Sampling methods}

The current study was carried out in Southern Laos, Attapeu province (Fig. 1) and the research subjects were from a minority ethnic group called Oy in Somsouk village which has a population of 1092 people and 174 households. The average income per year in this village is about 4million Kip ( 1 dollar $=\sim 8000 \mathrm{Kip}$ ) and this income is usually 


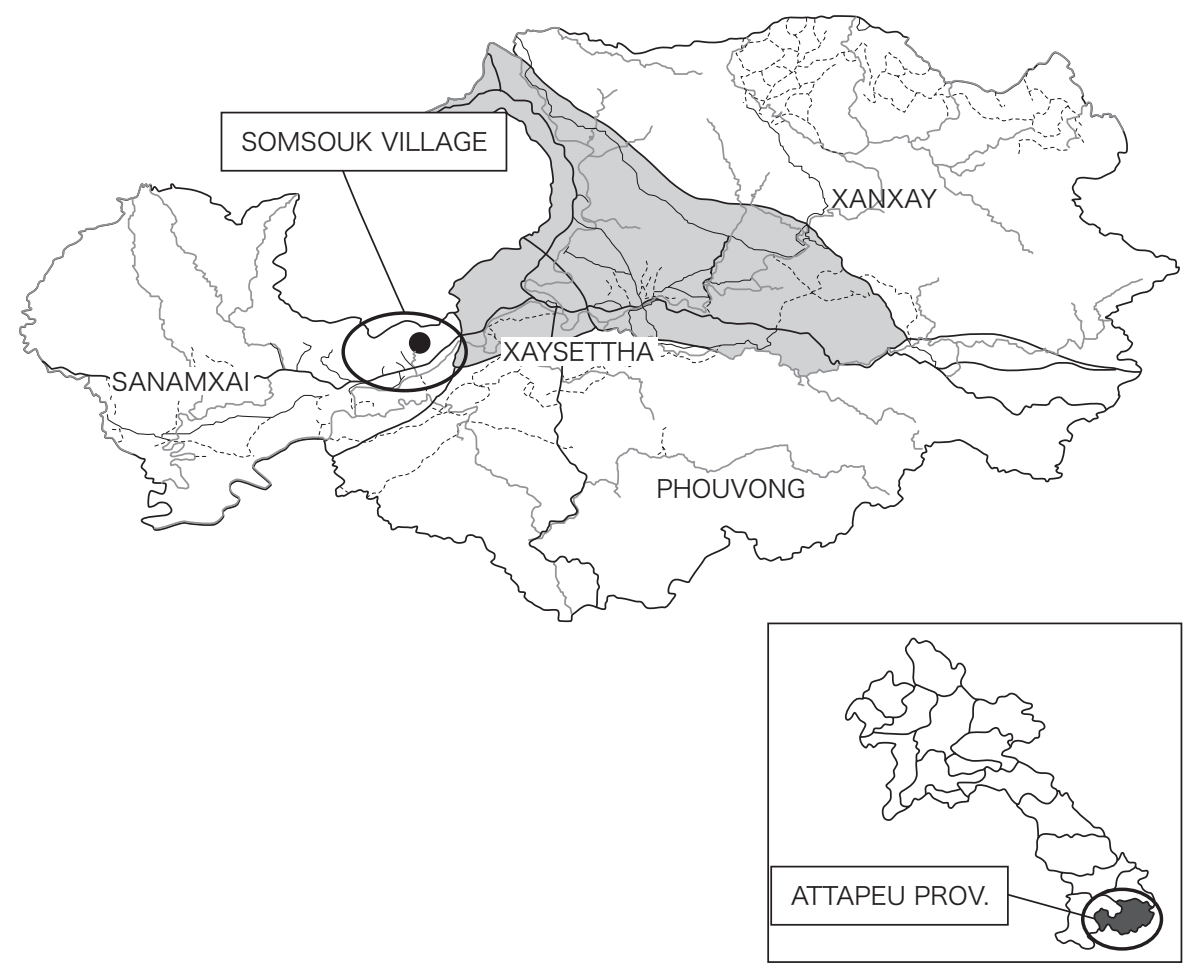

Fig. 1 Map of Attapeu province

got from selling rice and domestic animals like pigs, cattle and poultry and also from working part time. The main modes of food acquisition here include in village food exchange, market purchases, gardens, fish ponds traditionally known as Lumpar, hunting and picking food. Due to the fact that paddy field irrigation is through water that naturally flows from the mountains into the fields, depending on the climatic conditions, annually, many households have inadequate rice supply. Limited information is available on the nutritional status of children below 5 years in this area.

Two main reasons were based on to choose Somsouk village as a research area.

1) Somsouk is located in one of the poorest provinces in Laos, Attapeu province and so this would help give a clear picture of the food security situation. In addition to being poor, this province has one of the highest prevalences of malnutrition in the country but statistics for this particular village are not available.

2) Somsouk is prone to natural disasters because it lies in the Mekong delta. Every year, there occurs minor floods in this area and interest to do research here was increased by the occurrence of typhoon Ketsana.

A prospective cross-sectional survey using a pre-post comparison design was used for the study. All households with children between 6-59 months of age whose caretakers were willing to participate were included in the study

\section{Study design}

In August 2009 the first research was carried out on 42 households with children below 59 months of age. A year later, after the typhoon, the 
second research was carried out on 61 households ; including 18 of the 42 households that had been researched on the previous year. Methods used in the survey included ;

1) Anthropometric measurements

Weight and height measurements were carried out on the children. Weight was measured using a calibrated weighing scale and height was measured using a stadiometer.

2) General questionnaire

Face-to-face questionnaire interviews with child caregivers were conducted. First, a food frequency questionnaire (FFQ) where respondents were asked about how many days the respondent children had eaten particular foods in the seven days prior to data collection was used. The list of foods was determined by the research team prior to data collection. Next, household social economic situation (SES) data was obtained through interviewing the caregivers on sources of food and income and frequency of food insufficiency in the household.

3) Focus group discussions (FGD)

These were held in order to find out general information about the research area. Information on impacts of typhoon Ketsana on livelihoods of the people was also collected through these discussions. Focus group discussions were held with elderly men and women in the village who were willing to participate in the study.

\section{Data analysis}

WHO child growth standards were used to analyze anthropometric data by calculating $z^{-}$scores using Emergency Nutrition Assessment (ENA) for Standardized Monitoring and Assessment of Relief and Transitions (SMART) ; ENA for SMART software program. Children were classified as stunted if they had a height-for-age (HFA) $z^{-}$-score of $<-2$, moderate acute stunting if they had HFA $z^{-}$ scores between-2 and-3 $z^{-}$-scores and severely stunted if they had HFA $z^{-}$scores $<-3 z^{-}$scores of the median WHO growth standards. Children were classified as underweight if they had a weight for age (WFA) $z^{-}$-score of $<-2$, moderately underweight if they had WFA $z^{-}$scores between-2 and3 and severely underweight if WFA $z^{-}$scores were $<-3 \quad z^{-}$scores of the median WHO growth standards. Wasted children had weight-for-height (WFH) $z^{-}$scores of $<-2$, those that were moderately wasted had WFH $z^{-}$-scores between -2 and -3 and severely wasted children had $z^{-}$scores $<-3$. $Z^{-}$ scores below -2 generally show global acute malnutrition (GAM), between-2 and-3 $z^{-}$scores show moderate acute malnutrition (MAM) and $<-3 \mathrm{Z}^{-}$ scores show severe acute malnutrition (SAM).

SES and FFQ data was analysed using SPSS version 17 through application of McNemar as well as Pearson's Chi square tests.

Food consumption data was analysed through division of foods into eight food groups in order to find out the individual dietary diversity scores (IDDS) for the children. Data from the food frequency questionnaire was grouped into 8 food groups and the average number of food groups consumed by the subjects was calculated by summing eight food groups, namely cereals and roots, tubers ; Vitamin A rich vegetables ; Other vegetables and fruits; Meat and fish; eggs ; legumes ; Dairy products; Foods made with fat. The IDDS aims to capture nutrient adequacy. Many studies in several different age groups have shown that an increase in individual dietary diversity score is related to increased nutrient adequacy of the diet

\section{Ethical considerations}

This study was approved by the National Ethical Committee for Health Research, Ministry of Health, Laos. All study participants were informed about the purpose of the study. A verbal consent 
was taken from all study participants. For underfive children, an informed consent was taken from the parents

\section{Results}

Table 1 shows the gender and age distribution of subjects on whom data was collected. Data was collected from 85 children below 5 years of age pre-post typhoon Ketsana; 42 children pretyphoon and 61 post typhoon; 18 of the children were the same pre-post typhoon.

\section{Impact on food security}

Based on FGD data, household owned granaries were swept away by the floods, this leading to a marked reduction in household food stores. From the questionnaire data, it was seen that as a result of the typhoon, there was on average 30\% loss of domestic animals especially poultry and about 50\% reduction in the usual average rice production with $20 \%$ of the households harvesting no rice at all. Fish harvests also reduced because most of the fish were washed away into the main rivers by the strong floods although there was no major damage to Lumpar. All these resulted in strain on household food security. When asked about coping strategies used to mitigate the effects of typhoon Ketsana, the respondents said that four main coping strategies were applied. These included external assistance from the government and NGOs, in-village strategies, part time work and finding alternative food sources which is also called minor subsistence strategy in this paper. All the respondents received government aid right after the typhoon (50kgs of rice and $5 \mathrm{kgs}$ of rice seeds). These were distributed to each household by the village head. This strategy helped in improving household rice consumption. According to the villagers, in-village strategies were not considered as a new strategy because they are used in daily life. They
Table 1 Gender and Age distribution of the subjects

\begin{tabular}{lccc|ccc}
\hline & \multicolumn{3}{c|}{ Pre-typhoon Ketsana } & \multicolumn{3}{c}{ Post-typhoon Ketsana } \\
\hline Age & Boys & Girls & Total & Boys & Girls & Total \\
\hline 6-17 months & 0 & 0 & 0 & 4 & 5 & 9 \\
18-29 months & 12 & 0 & 12 & 9 & 9 & 18 \\
30-41 months & 7 & 3 & 10 & 12 & 7 & 19 \\
$42-53$ months & 9 & 7 & 16 & 4 & 4 & 8 \\
54-59 months & 0 & 4 & 4 & 2 & 5 & 7 \\
Total & 28 & 14 & 42 & 31 & 30 & 61 \\
\hline
\end{tabular}

included exchange of labor for food and money, borrowing and begging from relatives and use of common paddy field and Lumpar. In-village coping strategies were important in improving general food consumption. During non-planting and nonharvesting seasons, the villagers usually go out to neighboring villages and towns to do part time work. Such part time work involves construction, manual labor on farms and working in market places. Money from part time jobs helped in food acquisition, especially rice and fish, post typhoon Ketsana. Finding alternative food sources was used at household level to increase food supply within the household. This included increased picking of food from the forest and vegetables from paddy fields and also fishing from main rivers as opposed to the usual Lumpar. These activities helped in improving vegetable and fish consumption.

\section{Impact on food consumption}

Rice, fish and vegetables are the main foods that constitute meals of people in this village. Figure 2 shows the number of food groups consumed weekly by children before and after typhoon Ketsana.

From figure 2, it can be seen that $100 \%$ of the children were able to consume food from atleast four food groups in 2009 and 5\% were even able to consume food from all the food groups. Data for weekly consumption in 2010, however, shows 


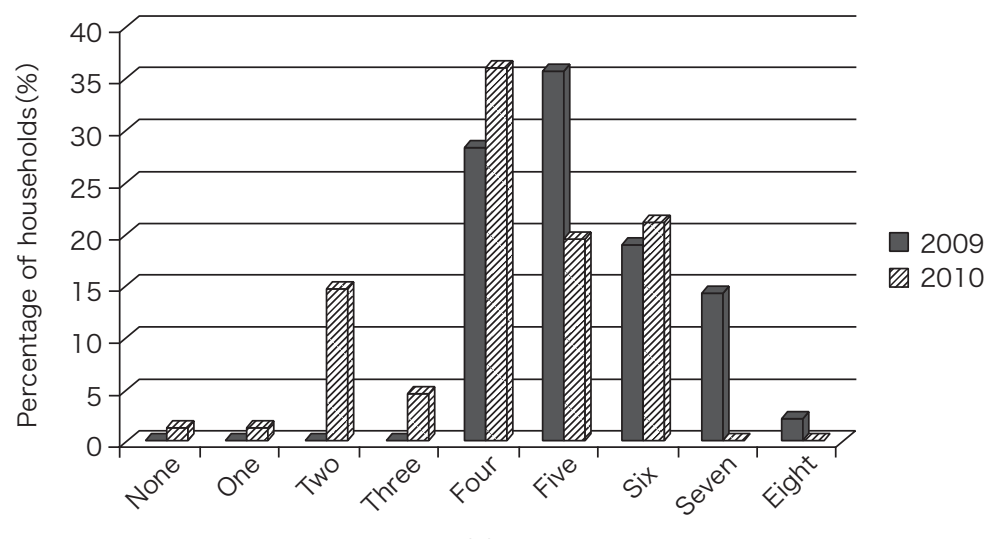

Number of food groups

Fig. 2 Number of food groups consumed weekly by children before and after typhoon Ketsana

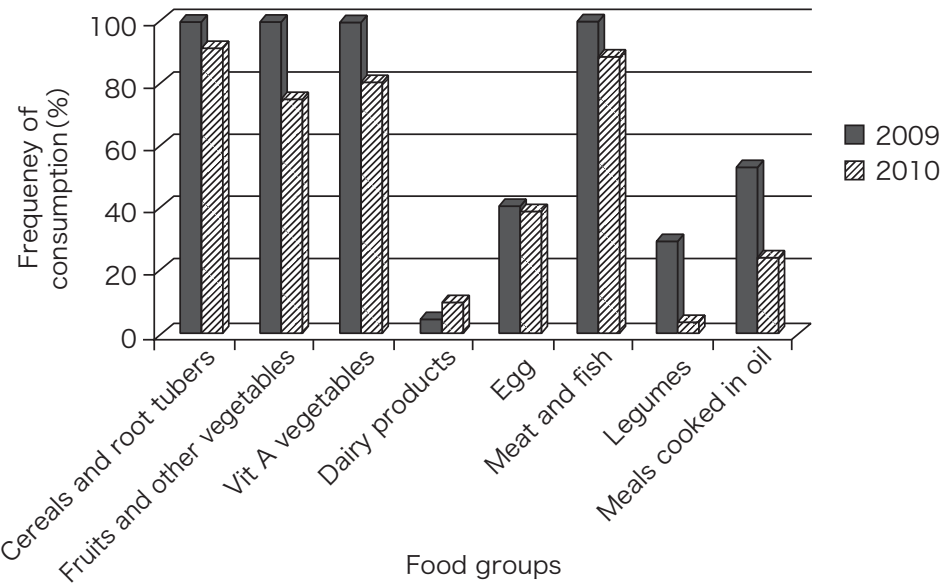

Fig. 3 Changes in children's weekly food consumption before and after typhoon Ketsana

reduced food consumption whereby on average, the subjects consumed food from 4 food groups with none of them consuming food from more than 6 food groups. It is seen that $3 \%$ of the subjects consumed food from as few as one food group in 2010.

Figure 3 shows changes in children's weekly food consumption before and after typhoon Ketsana.

As is shown in fig. 3 there was a general reduc- tion in frequency of food consumption in 2010 for especially Vitamin A rich vegetables, fruits, other types of vegetables and legumes. Whereas $100 \%$ the respondents were able to consume foods from the cereal and root tuber group, vitamin $\mathrm{A}$ rich vegetables and meat and fish in the year before the occurrence of the typhoon, this was not possible post the typhoon. As mentioned earlier, rice, fish and vegetables are the main foods consumed in this ethnic group so reduced consumption post 


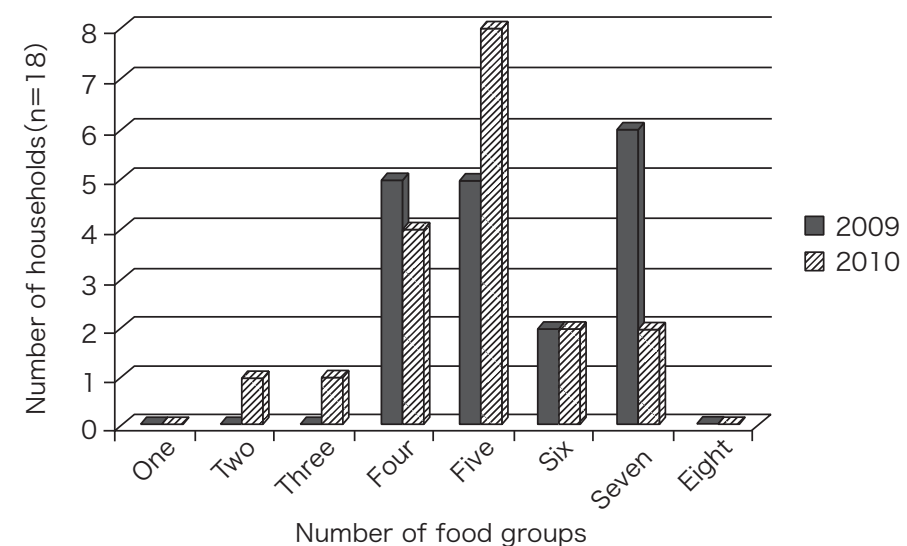

Fig. 4 Comparison of number of food groups consumed weekly by the same children before and after typhoon Ketsana

typhoon Ketsana could have had a severe impact on the health and nutritional status of the children.

Figure 4 shows comparison of number of food groups consumed weekly by the same children before and after typhoon Ketsana.

Comparing food consumption frequency pre $^{-}$ post typhoon Ketsana of 18 children, it can be seen that food consumption was generally better before the typhoon occurred. This can be clarified with the fact that as seen from fig. 4, $100 \%$ of the subjects were seen to have consumed foods from at least four food groups in comparison to $11 \%$ of the subjects post typhoon Ketsana who consumed foods from less than 4 food groups. $33 \%$ of the respondents were seen to have consumed seven food groups which were quite many since only $11 \%$ of the subjects consumed food from seven food groups post the typhoon. None of the respondents were able to consume food from all the eight food groups for both pre and post typhoon Ketsana. Pearson's Chi square test however showed no significant difference between food consumption frequency of the 18 respondents in 2009 and 2010 (p> $0.05)$

\section{Impact on nutritional status}

Table 2 shows global acute malnutrition (GAM), moderate acute malnutrition (MAM) and severe acute malnutrition (SAM) of the subjects by sex (pre-typhoon $=42$ respondents and post typhoon Ketsana $=61$ respondents). 18 of the respondents were the same pre-post typhoon.

As shown in Table 2, the prevalence of wasting prior to the typhoon was $33.3 \%$ whereas the prevalence of stunting was $71.4 \%$ and that of underweight $52.4 \%$. Post typhoon Ketsana, the prevalence of wasting was seen to have reduced to $24.6 \%$, stunting increased slightly to $72.1 \%$ and underweight reduced to $49.2 \%$.

The prevalence of stunting and underweight was seen to be high among the subjects for both pre as well as post typhoon Ketsana.

Table 3 shows comparison of prevalence of wasting, stunting and underweight pre-post typhoon Ketsana in 18 similar subjects extracted from table 2. Among the 18 children compared pre-post typhoon Ketsana, the prevalence of wasting was seen to be $27.8 \%$ pre typhoon Ketsana as opposed to $11.1 \%$ post the typhoon. Stunting prevalence reduced from $66.7 \%$ pre typhoon Ketsana to 61.1\% post typhoon Ketsana whereas underweight 
Table 2 Prevalence of wasting, stunting and underweight before and after typhoon Ketsana

\begin{tabular}{|c|c|c|c|c|c|c|c|}
\hline & \multirow{2}{*}{ Sex } & \multicolumn{3}{|c|}{ Pre-Typhoon Ketsana $(n=42)$} & \multicolumn{3}{|c|}{ Post-Typhoon Ketsana $(n=61)$} \\
\hline & & Wasting & Stunting & Underweight & Wasting & Stunting & Underweight \\
\hline \multirow{3}{*}{$\begin{array}{c}\text { Normal } \\
\mathrm{z}^{-} \text {scores } \\
\text { n }(\%)\end{array}$} & All & $28(66.7)$ & $12(28.6)$ & $20(47.6)$ & $46(75.4)$ & $17(27.9)$ & $31(50.8)$ \\
\hline & Boys & $20(71.4)$ & $11(39.3)$ & $13(46.4)$ & $23(74.2)$ & $8(25.8)$ & $14(45.2)$ \\
\hline & Girls & $8(57.1)$ & $1(7.8)$ & $7(50.0)$ & $23(76.7)$ & $9(30.0)$ & $17(56.7)$ \\
\hline \multirow{3}{*}{$\begin{array}{l}\mathrm{GAM}^{1)} \\
\mathrm{n}(\%)\end{array}$} & All & $14(33.3)$ & $30(71.4)$ & $22(52.4)$ & $15(24.6)$ & $44(72.1)$ & $30(49.2)$ \\
\hline & Boys & $8(28.6)$ & $17(60.7)$ & $15(53.6)$ & $8(25.8)$ & $23(74.2)$ & $17(54.8)$ \\
\hline & Girls & $6(42.9)$ & $13(92.2)$ & $7(50.0)$ & $7(23.3)$ & $21 \quad(70.0)$ & 13 (43.3) \\
\hline \multirow{3}{*}{$\begin{array}{l}\mathrm{MAM}^{2)} \\
\mathrm{n}(\%)\end{array}$} & All & $7 \quad(16.7)$ & $17(40.5)$ & $12(28.6)$ & $4(6.6)$ & $20(32.8)$ & $22(36.1)$ \\
\hline & Boys & $4(14.3)$ & $8(28.6)$ & $10(35.7)$ & $2(6.5)$ & $9(29.0)$ & $12(38.7)$ \\
\hline & Girls & $3(21.4)$ & $9(64.3)$ & $2(14.3)$ & $2(6.7)$ & $11(36.7)$ & $10(33.3)$ \\
\hline \multirow{3}{*}{$\begin{array}{l}\mathrm{SAM}^{3)} \\
\mathrm{n} \quad \%)\end{array}$} & All & $7(16.7)$ & $13(31.0)$ & $10(23.8)$ & $11(18.0)$ & $24(39.3)$ & $8(13.1)$ \\
\hline & Boys & $4(14.3)$ & $9(32.1)$ & $5 \quad(17.9)$ & $6(19.4)$ & $14(45.2)$ & $5 \quad(16.1)$ \\
\hline & Girls & 3 (21.4) & $4(28.6)$ & $5(35.7)$ & $5(16.7)$ & $10(33.3)$ & $3(10.0)$ \\
\hline
\end{tabular}

${ }^{1)}$ Global acute malnutrition entails both moderate acute malnutrition and severe acute malnutrition.

${ }^{2)}$ Moderate Acute Malnutrition (MAM) is GAM between -2 and $-3 \mathrm{SD}$ or 70 th-79th percentile.

${ }^{3)}$ Severe Acute Malnutrition (SAM) is GAM less than $-3 \mathrm{SD}$ or below the 70 th percentile

Table 3 Comparison of prevalence of wasting, stunting and underweight of the same children before and after typhoon Ketsana

\begin{tabular}{clrrr|rrr}
\hline & \multirow{2}{*}{ Sex } & \multicolumn{2}{c|}{ Pre-Typhoon Ketsana $(\mathrm{n}=18)$} & \multicolumn{3}{c}{ Post-Typhoon Ketsana $(\mathrm{n}=18)$} \\
\cline { 3 - 8 } & & Wasting & Stunting & Underweight & Wasting & Stunting & Underweight \\
\hline Normal & All & $13(72.2)$ & $6(33.3)$ & $8(44.4)$ & $16(88.9)$ & $7(38.9)$ & $8(44.4)$ \\
z-scores & Boys & $7(66.7)$ & $4(41.7)$ & $4(41.7)$ & $10(90.9)$ & $5(45.5)$ & $4(36.4)$ \\
$\mathrm{n}(\%)$ & Girls & $6(83.3)$ & $2(16.7)$ & $4(57.2)$ & $6(85.7)$ & $2(28.6)$ & $4(57.1)$ \\
\hline \multirow{2}{*}{ GAM $^{1)}$} & All & $5(27.8)^{*}$ & $12(66.7)$ & $10(55.6)$ & $2(11.1)$ & $11(61.1)$ & $10(55.6)$ \\
$\mathrm{n}(\%)$ & Boys & $4(33.3)$ & $7(58.3)$ & $7(58.3)$ & $1(9.1)$ & $6(54.5)$ & $7(63.6)$ \\
& Girls & $1(16.7)$ & $5(83.3)$ & $3(42.8)$ & $1(14.3)$ & $5(71.4)$ & $3(42.9)$ \\
\hline \multirow{2}{*}{ MAM $^{2)}$} & All & $3(16.7)$ & $8(44.4)$ & $6(33.3)$ & $2(11.1)$ & $6(33.3)$ & $7(38.9)$ \\
$\mathrm{n}(\%)$ & Boys & $2(16.7)$ & $5(41.7)$ & $4(33.3)$ & $1(9.1)$ & $3(27.3)$ & $5(45.5)$ \\
& Girls & $1(16.7)$ & $3(50.0)$ & $2(33.3)$ & $1(14.3)$ & $3(42.9)$ & $2(28.6)$ \\
\hline \multirow{2}{*}{ SAM $^{3)}$} & All & $2(11.1)$ & $4(22.2)$ & $4(22.2)$ & $0(0.0)$ & $5(27.8)$ & $3(16.7)$ \\
$\mathrm{n}(\%)$ & Boys & $2(16.7)$ & $2(16.7)$ & $3(25.0)$ & $0(0.0)$ & $3(27.3)$ & $2(18.2)$ \\
& Girls & $0(0.0)$ & $2(33.3)$ & $1(16.7)$ & $0(0.0)$ & $2(28.6)$ & $1(14.3)$ \\
\hline
\end{tabular}

${ }^{*}$ Significant change at $\mathrm{p}<0.001$

${ }^{1)}$ Global acute malnutrition entails both moderate acute malnutrition and severe acute malnutrition.

${ }^{2)}$ Moderate Acute Malnutrition (MAM) is GAM between -2 and $-3 \mathrm{SD}$ or 70 th-79th percentile.

${ }^{3)}$ Severe Acute Malnutrition (SAM) is GAM less than $-3 \mathrm{SD}$ or below the 70 th percentile

was $55.6 \%$ pre and $55.6 \%$ post the typhoon.

Using a McNemar test, it was seen that the prevalence of wasting significantly decreased prepost typhoon Ketsana $(\mathrm{p}<0.01)$ whereas the preva- lence of stunting and underweight didn't significantly change pre-post typhoon Ketsana ( $\mathrm{p}>$ 0.05). Wasting was generally more prevalent among boys $(33.3 \%$ pre and $9.1 \%$ post typhoon 
Ketsana). This was also the same for underweight and stunting.

\section{Discussion}

This study was conducted to assess the household food security and nutritional status of children below 5 years pre-post typhoon Ketsana and to also compare pre-post nutritional status and food consumption frequencies of some of the subjects inorder to find out whether there were any changes as a result of the typhoon. To achieve this, both qualitative and quantitative data was collected from respondents who were willing to participate in this study in an ethnic minority group called $\mathrm{Oy}$ in southern Laos. Before data collection, our hypothesis was that food consumption had reduced as a result of the typhoon and in turn, the nutritional status of the children had become poorer.

Based on our findings, there was major impact on the already strained household food security as a result of typhoon Ketsana. Due to the heavy rains, a number of households lost their rice stock, paddy fields as well as their domestic animals. This led to reduced food intake. Currie and Stabile (2003) state that there are a number of observational studies in North America which provide empirical support for the view that socioeconomic status is a relevant determinant of children's health. Since the household socioeconomic situation in this area had been affected by the typhoon, there was likely to be an effect on the health and thus the nutritional status of the children in this area. In order to reverse or control these effects, coping methods had to be put in place. According to our findings, various coping strategies were applied by the household members as well as female caregivers in order to overcome food insufficiency within the households. These included invillage strategies, finding alternative food sources, government aid and doing part-time work in order to buy food.

From the results, the prevalence of stunting and underweight, although not statistically significant, was stable and wasting prevalence significantly decreased after the typhoon even though food consumption was affected by the typhoon so ideally the nutritional status was supposed to have become worse than before the typhoon. As seen from the results, shock from the typhoon led to use of a number of strategies in order to maintain food consumption so this could have allowed for slightly quicker growth thus stability in stunting and underweight prevalence and decrease in prevalence of wasting. Coping strategies might not only have helped in maintaining consumption frequency but also improved household dietary diversity hence stability of nutritional status.

There was generally high prevalence of malnutrition pre-post typhoon Ketsana. This indicates a deep problem in this area. According to Pernille (2006), food security in Laos is synonymous with rice security and yet rice security does not necessarily lead to better diets and a reduction in malnutrition rates. As mentioned earlier, the main foods consumed in Somsouk village include rice, fish and low amounts of vegetables. This lack of dietary diversity could be one of the root causes of such a high prevalence of malnutrition in this area. There was also an exceptionally high prevalence of stunting both pre and post typhoon Ketsana. According to Van de Poel et al. (2008), stunting is considered as a reliable indicator of long-standing undernutrition in childhood. This high prevalence of stunting both before and after the typhoon Ketsana indicates a chronic food shortage and confirms the presence of long lasting poor nutrition as well as chronic household food insecurity in this area. Results post typhoon Ketsana indicate almost no change in the prevalence of stunting because stunting is an irreversible phenomena. 
That said, assessing food security and nutritional status is a complex task, especially if these are being related to natural disasters because the disasters occur suddenly and stop as suddenly as they occur. The uncertainty of natural disasters was the biggest limitation of this research because data could not be collected during or soon after the disaster had occurred. In addition, little data is available in national records about the effects of this typhoon on especially the nutritional status of children below 5 years of age. Weakness in the evaluation design also prevents us from drawing firm conclusions about the typhoon impacts. A careful reassessment of the impacts of climatic and environmental changes on food security as well as nutritional status with more sensitive methodologies is needed to understand the scope of effect of the 2009 typhoon Ketsana on U5 nutritional status in Southern Laos.

Despite the above mentioned limitations, the results of this study once again stress the role played by natural disasters in the road to food insecurity and malnutrition in especially poor rural communities. The research findings, especially the coping strategies used to overcome the impacts on food consumption will form a platform for finding ways of mitigating effects of natural disasters before they actually occur because such is a very important strategy for alleviating the losses and severe impacts that such disasters have on people's health and livelihoods.

\section{Conclusion}

This study showed the relationship between natural disasters, typhoon Ketsana in this case, and household food security as well as malnutrition and also showed various strategies that household members used in order to alleviate the effects of natural disasters that could in turn result in malnutrition. This study provided a good example of impact of natural disasters ; however, it is needless to say that the success of the strategies used depends on the total amount of impacts incurred as well as the kinds of coping strategies used. If the impacts are far beyond the "typical" situation, people will lose the base of their livelihood.

\section{Acknowledgements}

This study was supported by funding from the Japanese ministry of education, culture, sports, science and technology (\#20530465). The authors would like to thank the Laos National Institute of Public health (NIOPH) staff as well as the mothers and children who participated in this study.

\section{References}

Akoto O, Pooja P, Spiro D, et al. (2010) Household food insecurity and nutritional status of children aged 6 to 23 months in Kailai district of Nepal, Food and Nutrition Bulletin, 31, 483-494

Black RE, Bhutta LH, Caulfield ZA, et al. (2008) For the maternal and child nutrition study group, Maternal and child undernutrition and Survival, Lancet, 371, $417-440$

Currie J and Stabile M (2003) Socioeconomic status and child health : Why is the relationship stronger for older children? American Economic Review, 93, 1813-1823

Deolalikar A (2005) Poverty and Child malnutrition in Bangladesh, J Dev Soc, 21, 1-2

Foster A (1995) Prices, credit markets and child growth in low income rural areas, Economic Journal, 105, 551-570

Hoddinot J and Kinsey B (2001) Child growth in the time of drought, Oxf Bull Econ Stat, 63, 409-436

Ministry of Health of the Government of the Lao PDR, National Statistical Centre (NSC) of the Committee for Planning and Investment, UNICEF (2006) Multiple Indicator Cluster Survey (MICS)

Ministry of Health (2009) National Nutritional Strategy and Plan of Action 2010-2015

Pan American Health Organization (PAHO) (2000) Natural disasters : Protecting the public's health

Pelletier D, Frongillo E and Habicht JP (1993) Epidemiologic evidence for a potentiating effect of malnutrition on child mortality, Am J Public Health, 83, 1130- 
1133

Pernille MD (2006) Understanding malnutrition and rural food composition in Lao PDR, J Food Compost Anal, 19, 763-764

Strauss J and Thomas D (1998) Health, nutrition, and economic development, J Econ Lit, 36, 766-817

United Nations (2009) United Nations System High level task force report
Van de Poel E, Hosseinpoor AR, Speybrocck N, et al. (2008) Socioeconomic inequality in malnutrition in developing countries, Bull World Health Organ, 86, 282-291

WFP Lao PDR, Vulnerability Analysis and Mapping Branch (2007) Comprehensive Food Security and Vulnerability Analysis (CFSVA)

(Received 8.11.2011 ; Accepted 3.1.2013) 